\title{
Perfil Discente e o Desempenho Acadêmico dos Cursos de Ciências Contábeis das Universidades Federais Brasileiras
}

\section{Student Profile and Academic Performance of Accounting Science Courses of Brazilian Federal Universities}

\author{
GEISON CALYO VARELA DE MELO D \\ MARIZA CAMILA DE MIRANDA D \\ SANDRA MARIA DOS SANTOS \\ ANA MARIA FONTENELLE CATRIB D \\ AUGUSTO CÉZAR AQUINO CABRAL D
}

\section{RESUMO}

Nas últimas décadas, as discussões sobre desempenho acadêmico no ensino superior foram acentuadas e cada vez mais, buscou-se analisar as variáveis que exercem influência no processo de avaliação, dentre elas, variáveis ligadas ao perfil discente. Dessa forma, o objetivo da pesquisa é identificar a relação entre o perfil discente e o desempenho acadêmico dos cursos de Ciências Contábeis das Universidades Federais Brasileiras. Para tanto, foi desenvolvido um estudo descritivo, explicativo, quantitativo e documental, com um total de 40 cursos de Ciências Contábeis das Universidades Federais e 11.566 discentes que se submeteram ao ENADE nos últimos três triênios de avaliação, referentes aos anos de 2012, 2015 e 2018. Pelos resultados, foi possível traçar um perfil sociodemográfico (sexo masculino, faixa etária entre 21 e 30 anos, brancos, trabalham integralmente e possuem renda entre 3 
a 4,5 salários mínimos) e escolar (estudaram todo o ensino médio em escola pública tradicional, os pais possuem escolaridade de ensino médio e se dedicam entre uma e três horas de estudo fora de sala de aula) dos discentes. Infere-se ainda, que essas variáveis analisadas estão relacionadas significativamente e são consideradas como influenciadoras do desempenho acadêmico dos cursos de Ciências Contábeis das universidades federais brasileiras.

Palavras-chave: Perfil Discente. Desempenho Acadêmico. Ciências Contábeis.

\section{Abstract}

In the last decades, discussions about academic performance in higher education have been accentuated and, increasingly, it has sought to analyze the variables that influence the evaluation process, among them, variables linked to the student profile. Thus, the objective of the research is to identify the relationship between the student profile and the academic performance of the Accounting Sciences courses at the Brazilian Federal Universities. To this end, a descriptive, explanatory, quantitative and documentary study was developed, with a total of 40 Accounting Sciences courses from Federal Universities and 11,566 students who underwent ENADE in the last three assessment trienniums, referring to the years 2012, 2015 and 2018. Based on the results, it was possible to draw a sociodemographic profile (male, aged between 21 and 30 years old, white, working full-time and earning between 3 and 4.5 minimum wages) and school (studied all high school in a public school traditionally, parents have high school education and dedicate between one and three hours of study outside the classroom) of the students. It is also inferred that these analyzed variables are significantly related and are considered to influence the academic performance of Accounting courses at Brazilian federal universities.

Keywords: Student Profile. Academic achievement. Accounting Sciences.

\section{INTRODUÇÃo}

No cenário brasileiro, o ensino superior percorreu um caminho lento de organização e desenvolvimento, que somente a partir da década de 1960 houve um impulso na expansão e estruturação do 
ensino (VASCONCELOS, 2010). Nos anos seguintes, o ensino superior passou por mudanças significativas em todos os seus eixos, de ensino, pesquisa e extensão, voltadas especialmente para atender ao seu público principal, os discentes (MIRANDA et al., 2015).

Essas mudanças impulsionaram a oferta do ensino superior e proporcionaram maior ingresso de discentes, que representam um público diversificado em relação as questões sociodemográficas, econômicas, educacionais, profissionais e expectativas futuras, mostrando que a expansão do ensino superior alcançou as mais diversas classes sociais em todas as regiões do país (MENDONÇA NETO; VIEIRA; ANTUNES, 2018; NEVES; SAMPAIO; HERINGER, 2018).

Assim, a discussão acerca dos atributos que compõem o perfil discente se caracteriza como sendo necessária para a reflexão do que exerce influência sobre o desempenho acadêmico, bem como pode exercer um importante papel para o ingresso deste discente no mercado de trabalho (ALANZI; ALFRAIH, 2017; ABINA; UTHMAN, 2018). Em complemento, Wang (2017) afirma que o desempenho acadêmico é a maneira como o discente responde a objetivos previamente definidos em busca de sua realização acadêmica.

Nesse contexto, o curso de Ciências Contábeis se apresenta como relevante para o processo evolutivo do ensino superior, tendo em vista o contexto histórico que a Contabilidade está inserida, desde os períodos mais remotos da humanidade até os dias atuais e a relação exercida no âmbito educacional (KAWACHE; VIEIRA; MENDONÇA NETO, 2015), a priori com a criação dos cursos de graduação, seguido pelos cursos de pós-graduação stricto sensu e assim, faz-se necessária a discussão do desempenho acadêmico na área em diversas dimensões, dentre elas, os aspectos relacionados ao perfil discente (RISTOFF, 2003; SANTOS; CERQUEIRA, 2009; IUDÍCIBUS, 2015).

Dessa forma, o desenvolvimento da pesquisa encontra-se norteado pela seguinte problemática: Qual a relação entre o perfil discente e o desempenho acadêmico dos cursos de Ciências Contábeis das Universidades Federais Brasileiras? Para tanto, o objetivo geral da pesquisa consiste em identificar a relação entre o perfil discente e o desempenho acadêmico dos cursos de Ciências Contábeis das Universidades Federais Brasileiras. Como objetivo adicional, busca-se 
verificar o perfil dos discentes dos cursos de Ciências Contábeis das Universidades Federais Brasileiras.

A justificativa para o desenvolvimento do estudo se concentra na busca por preencher lacunas existentes na área de Ensino da Contabilidade no Brasil que ainda é considerada escassa, dado a complexidade do tema e tendo em vista a necessidade de se conhecer o perfil discente, principal público do ensino superior e apresenta-se de forma diversificada em relação as características sociodemográficas, educacionais e econômicas, podendo assim, influenciar o desempenho acadêmico do ensino superior e ser capaz de participar do processo de avaliação do ensino, com particularidades que somente competem ao discente (GIL, 2012; SANTOS, 2012; FERREIRA, 2015).

Sendo assim, a pesquisa apresenta contribuições nos âmbitos teórico e prático, no incremento das discussões relacionada ao tema e ampliar a produção científica na área, tendo em vista a incipiência de estudos que apresentem fatores influenciadores do desempenho acadêmico na visão de atributos que competem ao corpo discente das instituições de ensino, bem como poder auxiliar na busca por melhorias no processo de ensino-aprendizagem nos âmbitos do ensino, pesquisa e extensão, voltados principalmente para o público discente e estão relacionados com o desempenho acadêmico.

\section{REVISÃo DE LITERATURA}

\subsection{O curso de Ciências Contábeis}

Num contexto histórico, a Contabilidade apresenta-se como sendo tão antiga que assemelha-se o seu desenvolvimento ao surgimento do homem enquanto ser pensante, mesmo que utilizasse de técnicas mais rudimentares, que foram aprimoradas ao longo dos anos, assim, a evolução da contabilidade enquanto ciência, trouxe reflexos no âmbito educacional, no nível superior de graduação do curso de Ciências Contábeis (IUDÍCIBUS, 2015).

Ao longo dos anos, o ensino da contabilidade sofreu influência de diversos fatores, fatos marcantes e acontecimentos que garantiram a sua evolução e relevância no cenário do ensino superior, mesmo que considerado um desenvolvimento tardio e com a existência de 
lacunas em relação a oferta/demanda do curso, o ensino da contabilidade apresenta-se num contexto evolutivo de sucesso, acompanhando as tendências mundiais existentes (SILVA; ROSA, 2016).

A criação da Faculdade de Economia, Administração e Contabilidade da USP (FEA-USP), por volta de 1946, foi considerada um marco na evolução do curso de Ciências Contábeis no país, em que o ensino da contabilidade passou a ser realmente desenvolvido de forma concreta como curso de nível superior e todos os desdobramentos que envolvem os aspectos de ensino, pesquisa e extensão na área (IUDÍCIBUS, 2015).

Não somente houve evolução do curso de graduação em Ciências Contábeis, como também, a partir da década de 1970, deu-se início ao desenvolvimento dos primeiros programas de pós-graduação Stricto Sensu na área de Contabilidade, iniciado também pela FEA/USP com o programa de pós-graduação Stricto Sensu na modalidade de Mestrado e posteriormente, a implantação do curso de Doutorado em Ciências Contábeis (SOARES et al., 2018).

As discussões acerca do ensino superior estão cada vez mais frequentes, dentre elas, voltadas para o desempenho acadêmico, em que o curso de Ciências Contábeis se faz presente nas questões relativas à avaliação dos cursos, considerada como instrumento utilizado com maior frequência para verificar a eficácia do processo ensino-aprendizagem nos cursos de ensino superior (NOGUEIRA et al., 2013).

\subsection{Perfil discente e desempenho acadêmico}

Dentre as discussões que permeiam no ensino superior no Brasil e no mundo, as questões relativas à evolução do perfil discente se fazem presentes no processo de ensino-aprendizagem e como seus reflexos podem influenciar aspectos referentes a avaliação do desempenho acadêmico (MIRANDA; ARAUJO; MIRANDA, 2015).

A evolução ocorrida no ensino superior, nas últimas décadas, tomou proporções significativas no que diz respeito ao acesso, ensino, avaliação, etc., relacionadas a expansão do número de instituições de ensino, de cursos e matrículas, ao aprimoramento do processo de ensino-aprendizagem e as questões relativas a avaliação, em que a proxy perfil discente apresenta-se como um grupo 
de variáveis determinantes do desempenho acadêmico (DAS, 2014; MANIATES, 2017).

O perfil discente dos cursos de ensino superior apresentou evolução ao longo dos anos, caracterizado como um público diversificado, ao mesmo tempo que possuem diferenças individuais e uma personalidade formada que influenciam no seu processo de aprendizagem, além do mais, carregam em si uma bagagem anterior de nível intelectual e aptidões específicas, que somadas ao conhecimento adquirido no ensino superior, possuem relação importante no desempenho acadêmico das instituições de ensino (GIL, 2012).

Assim, considera-se o desempenho acadêmico mensurado por meio de um conjunto de fatores que reúne características relativas ao corpo discente, corpo docente e da instituição de ensino, que vão de encontro ao perfil sociodemográfico dos discentes, a formação e desenvolvimento profissional docente e ao suporte que a instituição oferece ao seu público, analisados conjuntamente ou de forma individual (GLEWWE et al., 2011; FERREIRA, 2015)

Por meio da avaliação do desempenho acadêmico, é possível traçar estratégias com o intuito de buscar melhorias no processo de ensino-aprendizagem e no desenvolvimento de projetos e políticas educacionais, tendo em vista que o desempenho acadêmico não é uma preocupação somente das instituições e docentes, mas também do mercado que receberá os profissionais provenientes das instituições (RIBEIRO, 2011; UYAR; GÜNGÖRMÜŞ, 2011).

Dessa forma, é notória a necessidade de se conhecer os fatores determinantes do desempenho acadêmico, à medida que se passou a ter maior atenção à qualidade do ensino superior e do crescimento da oferta de cursos como o de Ciências Contábeis, que acompanhou a evolução do ensino superior e necessita também de políticas que visem melhorias em seu processo de ensino (ARAÚJO et al., 2013; ALVES; FARIAS; FARIAS, 2015).

\subsection{Estudos empíricos sobre Perfil Discente e Desempenho Acadêmico}

Com o intuito de se analisar a evolução da pesquisa científica na área, realizou-se um levantamento bibliográfico nas plataformas digitais do Portal de Periódicos da CAPES e no Sistema SPELL, vi- 
sando identificar estudos relacionados ao desempenho acadêmico com foco para os aspectos relativos ao perfil discente dos cursos de Ciências Contábeis.

Cornachione Junior et al. (2010) investigaram a existência de associação entre elementos atributivos comuns na literatura e o desempenho acadêmico de alunos da graduação em ciências contábeis, e por meio de uma pesquisa descritiva, exploratória e quantitativa, com discentes de universidades federais de diversos estados do país, constatou-se que a maioria dos alunos com desempenho superior, o atribuem ao seu próprio esforço, enquanto uma minoria o relaciona a causas externas, já o desempenho superior é mais atribuído a causas internas que o desempenho inferior, com uma interessante idiossincrasia entre os gêneros.

Araújo et al. (2013) realizaram um estudo com discentes do curso de Ciências Contábeis de uma IES privada de Belo Horizonte para identificar se o desempenho acadêmico, mensurado pela nota final das disciplinas, é explicado pelas variáveis frequência nas aulas, idade, sexo, natureza e tipo da disciplina. A pesquisa evidenciou que existe uma relação forte e positivo entre a variável dependente e o conjunto de independentes do modelo, bem como, as maiores correlações foram observadas nas variáveis relacionadas às disciplinas da IES pesquisada.

Miranda et al. (2014) investigaram a associação entre variáveis comportamentais e desempenho acadêmico de 494 alunos do curso de ciências contábeis de uma universidade pública brasileira. Os resultados evidenciaram que a variável hábito de fumar tem impacto direto sobre o desempenho; o desempenho das mulheres é superior ao dos homens; o convívio com pessoas de influência e a crença no destino está relacionada com o desempenho; alunos com idade de 20 a 40 anos têm rendimento inferior aos demais e o tempo de experiência está relacionada diretamente com o desempenho.

Camargo et al. (2016) mensuraram o desempenho (proficiência) dos estudantes de Ciências Contábeis no ENADE por meio da Teoria da Resposta ao Item (TRI) e dessa forma, observou-se que os estudantes necessitam de domínios diversos à medida que mudavam de nível e os itens contidos na prova Enade representaram um alto grau de dificuldade para o grupo que realizou a prova, bem como, 
independente das características analisadas, os estudantes, em geral, apresentaram proficiências muito baixas.

Miranda, Dos Reis e Freitas (2017) analisaram a ansiedade entre estudantes de Ciências Contábeis de uma Universidade Pública Brasileira e sua relação com o desempenho acadêmico. Os resultados indicam que os estudantes mais ansiosos tendem a ficar mais ansiosos que os demais em momentos de avaliação, que as mulheres tendem a apresentar maior ansiedade que os homens e que os alunos mais ansiosos, de final de curso, homens e que não participaram de atividades acadêmicas tendem a apresentar rendimentos acadêmicos inferiores aos demais.

A partir dos estudos apresentados e com vista a complexidade da temática, percebe-se que ainda existe uma incipiência na produção científica no que se refere ao desenvolvimento de estudos sobre desempenho acadêmico dos cursos de Ciências Contábeis voltados para os aspectos relativos ao perfil dos discentes, reforçando ainda, a necessidade de extensão dessa discussão sobre a temática.

\section{Metodologia}

A presente pesquisa objetiva identificar a relação entre o perfil discente e o desempenho acadêmico dos cursos de Ciências Contábeis das Universidades Federais Brasileiras, dessa forma, o estudo caracteriza-se como sendo do tipo descritiva e explicativa, de natureza quantitativa e de procedimento documental.

O estudo possui uma amostra que abrange os cursos de Ciências Contábeis das universidades federais brasileiras e que realizaram o exame ENADE nos três últimos triênios de avaliação, referente aos anos de 2012, 2015 e 2018 e tiveram os seus discentes analisados, totalizando 40 cursos e compreendendo um total de 11.566 discentes.

A coleta dos dados ocorreu mediante a extração dos Microdados do ENADE dos triênios analisados, disponibilizados no site do Instituto Nacional de Estudos e Pesquisas Educacionais Anísio Teixeira (INEP). 


\section{Quadro 1 - Variáveis discentes utilizadas no estudo}

\begin{tabular}{|c|c|c|c|}
\hline VARIÁVEIS & OPERACIONALIZAÇÃO & COLETA & FUNDAMENTAÇÃO \\
\hline Sexo & $\begin{array}{l}1 \text { - Masculino } \\
2 \text { - Feminino }\end{array}$ & $\begin{array}{l}\text { Microdados } \\
\text { ENADE }\end{array}$ & $\begin{array}{l}\text { Cornachione Junior } \\
\text { et al. (2010); Ferreira } \\
(2015)\end{array}$ \\
\hline Idade & $\begin{array}{l}1 \text { - Até } 20 \text { anos } \\
2 \text { - Entre } 21 \text { e } 30 \text { anos } \\
3 \text { - Entre } 31 \text { e } 40 \text { anos } \\
4 \text { - Entre } 41 \text { e } 50 \text { anos } \\
5 \text { - Acima de } 50 \text { anos }\end{array}$ & $\begin{array}{l}\text { Microdados } \\
\text { ENADE }\end{array}$ & $\begin{array}{l}\text { Santos (2012); Ferrei- } \\
\text { ra (2015) }\end{array}$ \\
\hline Cor/etnia & $\begin{array}{l}1 \text { - Branco(a) } \\
2 \text { - Negro(a) } \\
3 \text { - Pardo(a)/mulato(a) } \\
4 \text { - Amarelo(a) } \\
5 \text { - Indígena }\end{array}$ & $\begin{array}{l}\text { Microdados } \\
\text { ENADE }\end{array}$ & $\begin{array}{l}\text { Vasconcelos (2010); } \\
\text { Ferreira (2015) }\end{array}$ \\
\hline $\begin{array}{l}\text { Atividade } \\
\text { remunerada }\end{array}$ & $\begin{array}{l}1 \text { - Não está trabalhando } \\
2 \text { - Trabalha eventualmente } \\
3 \text { - Trabalha até } 20 \mathrm{~h} \text { semanais } \\
4 \text { - Trabalha mais de } 20 \mathrm{~h} \text { e menos } \\
\text { de } 40 \text { h semanais } \\
5 \text { - Trabalha em tempo integral } \\
\text { (40h semanais) }\end{array}$ & $\begin{array}{l}\text { Microdados } \\
\text { ENADE }\end{array}$ & $\begin{array}{l}\text { Garkaz, Banimahd } \\
\text { e Emaelili (2011); } \\
\text { Ferreira (2015) }\end{array}$ \\
\hline $\begin{array}{l}\text { Renda } \\
\text { familiar }\end{array}$ & $\begin{array}{l}1 \text { - Até } 1,5 \text { salário mínimo } \\
2 \text { - De } 1,5 \text { a } 3 \text { salários mínimos } \\
3 \text { - De } 3 \text { a } 4,5 \text { salários mínimos } \\
4 \text { - De } 4,5 \text { a } 6 \text { salários mínimos } \\
5 \text { - De } 6 \text { a } 10 \text { salários mínimos } \\
6 \text { - De } 10 \text { a } 30 \text { salários mínimos } \\
7 \text { - Acima de } 30 \text { salários mínimos }\end{array}$ & $\begin{array}{l}\text { Microdados } \\
\text { ENADE }\end{array}$ & $\begin{array}{l}\text { Katsikas e Panagioti- } \\
\text { dis (2011); Nyikahad- } \\
\text { zoi et al. (2013) }\end{array}$ \\
\hline $\begin{array}{l}\text { Escolaridade } \\
\text { do pai }\end{array}$ & $\begin{array}{l}1 \text { - Nenhuma } \\
2 \text { - Ens. Fundamental: } 1^{\underline{o}} \text { ao } 5^{\underline{o}} \text { ano } \\
3 \text { - Ens. Fundamental: } 6^{0} \text { ao } 9^{\underline{0}} \text { ano } \\
4 \text { - Ensino Médio } \\
5 \text { - Ensino Superior }\end{array}$ & $\begin{array}{l}\text { Microdados } \\
\text { ENADE }\end{array}$ & $\begin{array}{l}\text { Vasconcelos (2010); } \\
\text { Ferreira (2015) }\end{array}$ \\
\hline $\begin{array}{l}\text { Escolaridade } \\
\text { da mãe }\end{array}$ & $\begin{array}{l}1 \text { - Nenhuma } \\
2 \text { - Ens. Fundamental: } 1^{\underline{0}} \text { ao } 5^{-0} \text { ano } \\
3 \text { - Ens. Fundamental: } 6^{0} \text { ao } 9^{-0} \text { ano } \\
4 \text { - Ensino Médio } \\
5 \text { - Ensino Superior }\end{array}$ & $\begin{array}{l}\text { Microdados } \\
\text { ENADE }\end{array}$ & $\begin{array}{l}\text { Vasconcelos (2010); } \\
\text { Ferreira (2015) }\end{array}$ \\
\hline
\end{tabular}




\begin{tabular}{|c|c|c|c|}
\hline $\begin{array}{l}\text { Tipo do En- } \\
\text { sino Médio }\end{array}$ & $\begin{array}{l}1 \text { - Todo em escola pública } \\
2 \text { - Todo em escola privada } \\
3 \text { - A maior parte em escola pública } \\
4 \text { - A maior parte em escola pri- } \\
\text { vada } \\
5 \text { - Parte no Brasil e parte no } \\
\text { exterior }\end{array}$ & $\begin{array}{l}\text { Microdados } \\
\text { ENADE }\end{array}$ & $\begin{array}{l}\text { Cornachione Junior et } \\
\text { al. (2010); Miranda et } \\
\text { al. (2015) }\end{array}$ \\
\hline $\begin{array}{l}\text { Modalidade } \\
\text { do Ensino } \\
\text { Médio }\end{array}$ & $\begin{array}{l}1 \text { - Ensino médio tradicional } \\
2 \text { - Profissionalizante técnico } \\
3 \text { - Profissionalizante magistério } \\
4 \text { - Educação de Jovens e Adultos } \\
\text { e/ou Supletivo } \\
5 \text { - Outra modalidade }\end{array}$ & $\begin{array}{l}\text { Microdados } \\
\text { ENADE }\end{array}$ & $\begin{array}{l}\text { Cornachione Junior et } \\
\text { al. (2010); Miranda et } \\
\text { al. (2015) }\end{array}$ \\
\hline $\begin{array}{l}\text { Horas de } \\
\text { estudo fora } \\
\text { da aula }\end{array}$ & $\begin{array}{l}1 \text { - Nenhuma } \\
2 \text { - De uma a três } \\
3 \text { - De quatro a sete } \\
4 \text { - De oito a doze } \\
5 \text { - Mais de doze }\end{array}$ & $\begin{array}{l}\text { Microdados } \\
\text { ENADE }\end{array}$ & $\begin{array}{l}\text { Nyikahadzoi et al. } \\
\text { (2013); Ferreira (2015) }\end{array}$ \\
\hline
\end{tabular}

Fonte: Elaborado pelos autores (2020).

Após a coleta, o tratamento dos dados foi realizado mediante as técnicas de estatística descritiva e correlação de Pearson, com todas as variáveis do estudo, para atingir os objetivos do estudo. Como apresentado no Quadro 2 a seguir.

Quadro 2 - Variáveis utilizadas na matriz de correlação

\begin{tabular}{|c|c|c|}
\hline DEFINIÇÃO & COMPOSIÇÃO & DEFINIÇÃO \\
\hline $\begin{array}{l}\text { Resempenho acadêmico } \\
\text { (Varlavel dependente) }\end{array}$ & NT_GERAL & $\begin{array}{l}\text { Notageral_do discente no exa- } \\
\text { me ENADE }\end{array}$ \\
\hline \multirow{10}{*}{$\begin{array}{l}\text { Zariáxeis discentes } \\
\text { (Variaveis independentes) }\end{array}$} & SEX_DISC & Sexo do discente \\
\hline & IDAD_DISC & Idade do discente \\
\hline & COR_ET & Cor/Etnia \\
\hline & AT_REM & Atividade remunerada \\
\hline & REND & Renda familiar \\
\hline & ESC_PAI & Escolaridade do pai \\
\hline & ESC_MAE & Escolaridade da mãe \\
\hline & TP_ENS & Tipo de ensino médio \\
\hline & MOD_ENS & Modalidade de ensino médio \\
\hline & HR_EST & $\begin{array}{l}\text { Horas de estudo fora de sala } \\
\text { de aula }\end{array}$ \\
\hline
\end{tabular}

Fonte: Elaborado pelos autores (2020). 
Posteriormente, realizou-se a tabulação dos dados por meio dos Softwares Microsoft Excel (versão Windows 10), $R$ Studio ( $R$ Development Core Team), EViews (versão 10) e Statistical Package for the Social Sciences - SPSS® (versão 25) e por fim, elaborou-se as tabelas no Software Microsoft Word (versão Windows 10), para facilitar a visualização e compreensão dos resultados.

\section{ANÁlise E DISCUSSÃo doS RESUltAdos}

Com o intuito de verificar o perfil dos discentes dos cursos de Ciências Contábeis das Universidades Federais Brasileiras, apresenta-se a quantidade de discentes convocados para realizarem a avaliação ENADE, além de apontar suas principais características e a nota geral que os mesmos obtiveram nos triênios analisados.

Tabela 1 - Quantidade de discentes convocados para o ENADE por região brasileira

\begin{tabular}{l|lll|l|l|l|l|l|l|}
\hline \multirow{2}{*}{ REGIÃO } & \multicolumn{2}{l}{2012} & \multicolumn{2}{l}{2015} & \multicolumn{2}{l|}{2018} & \multicolumn{2}{l|}{ TOTAL } & \\
\cline { 2 - 10 } & FREQ. & $\%$ & FREQ. & $\%$ & FREQ. & $\%$ & FREQ. & $\%$ \\
\hline NORTE & 491 & 11,8 & 582 & 14,0 & 415 & 12,8 & 1.488 & 12,9 \\
\hline NORDESTE & 1.731 & 41,6 & 1.608 & 38,7 & 1.268 & 39,0 & 4.607 & 39,8 \\
\hline CENTRO-OESTE & 479 & 11,5 & 526 & 12,7 & 476 & 14,7 & 1.481 & 12,8 \\
\hline SUDESTE & 873 & 21,0 & 861 & 20,7 & 800 & 24,6 & 2.534 & 21,9 \\
\hline SUL & 589 & 14,1 & 578 & 13,9 & 289 & 8,9 & 1.456 & 12,6 \\
\hline TOTAL & 4.163 & 100,0 & 4.155 & 100,0 & 3.248 & 100,0 & 11.566 & 100,0 \\
\hline
\end{tabular}

Fonte: Dados da Pesquisa (2020).

É possível perceber que houve uma queda no número de discentes que foram convocados para realizarem o ENADE, ao longo dos triênios analisados, principalmente no ano de 2018. Levando em consideração a análise conjunta dos três triênios e em relação a distribuição por região brasileira, a região Nordeste foi a que apresentou maior quantidade de discentes convocados, com média de $39,8 \%$ dos discentes convocados, seguida da região Sudeste com, aproximadamente, $22 \%$ do total de discentes e as demais regiões, apresentaram médias semelhantes, que variam de $12,6 \%$ a $12,9 \%$ dos discentes que foram convocados.

Após a análise do quantitativo de discentes convocados para a realização do ENADE, faz-se necessário conhecer o perfil dos discentes 
que participaram desse processo de avaliação dos últimos três triênios. Para melhor visualização, as características apresentadas foram divididas pelo seu perfil sociodemográfico e escolar, como exposto a seguir.

Tabela 2 - Perfil sociodemográfico dos discentes do ENADE

\begin{tabular}{|c|c|c|c|c|c|c|c|}
\hline \multirow{2}{*}{\multicolumn{2}{|c|}{$\begin{array}{l}\text { CARACTERÍSTICAS } \\
\text { FREQ. }\end{array}$}} & \multicolumn{2}{|l|}{2012} & \multicolumn{2}{|l|}{2015} & \multicolumn{2}{|l|}{2018} \\
\hline & & \multirow{2}{*}{$\begin{array}{l}\% \\
2.213\end{array}$} & \multirow{2}{*}{\begin{tabular}{|l|} 
FREQ. \\
53,2
\end{tabular}} & \multirow{2}{*}{$\begin{array}{ll}\% \\
2.075\end{array}$} & \multirow{2}{*}{\begin{tabular}{|l} 
FREQ. \\
49,9
\end{tabular}} & \multirow{2}{*}{$\begin{array}{ll}\% \\
1.695\end{array}$} & \multirow[b]{2}{*}{52,2} \\
\hline & Masculino & & & & & & \\
\hline SEXU & Feminino & 1.950 & 46,8 & 2.080 & 50,1 & 1.553 & 47,8 \\
\hline \multirow{5}{*}{ 岕 } & Até 20 anos & 48 & 1,2 & 58 & 1,4 & 8 & 0,2 \\
\hline & Entre 21 e 30 anos & 3.291 & 79,1 & 3.251 & 78,2 & 2.487 & 76,6 \\
\hline & Entre 31 e 40 anos & 651 & 15,6 & 673 & 16,2 & 565 & 17,4 \\
\hline & Entre 41 e 50 anos & 138 & 3,3 & 132 & 3,2 & 145 & 4,5 \\
\hline & Acima de 50 anos & 35 & 0,8 & 41 & 1,0 & 43 & 1,3 \\
\hline \multirow{6}{*}{ 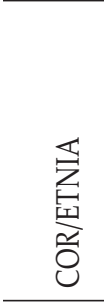 } & Branco(a) & 1.864 & 44,8 & 1.846 & 44,4 & 1.319 & 40,6 \\
\hline & Negro(a) & 266 & 6,4 & 344 & 8,3 & 279 & 8,6 \\
\hline & Pardo(a)/mulato(a) & 1.223 & 29,4 & 1.428 & 34,4 & 1.239 & 38,1 \\
\hline & Amarelo(a) & 40 & 1,0 & 47 & 1,1 & 89 & 2,7 \\
\hline & Indígena & 20 & 0,5 & 16 & 0,4 & 11 & 0,3 \\
\hline & Não respondeu & 750 & 18,0 & 474 & 11,4 & 311 & 9,6 \\
\hline \multirow{6}{*}{ 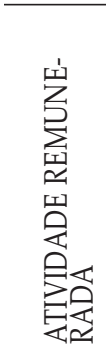 } & Não está trabalhando & 701 & 16,8 & 911 & 21,9 & 903 & 27,8 \\
\hline & Trabalha eventualmente & 72 & 1,7 & 77 & 1,9 & 107 & 3,3 \\
\hline & Trabalha até $20 \mathrm{~h} /$ semanais & 150 & 3,6 & 201 & 4,8 & 150 & 4,6 \\
\hline & $\begin{array}{l}\text { Trabalha mais de } 20 \mathrm{~h} \mathrm{e} \\
\text { menos de } 40 \mathrm{~h} \text { semanais }\end{array}$ & 562 & 13,5 & 507 & 12,2 & 394 & 12,1 \\
\hline & $\begin{array}{l}\text { Trabalha integralmente (40h } \\
\text { semanais ou mais) }\end{array}$ & 1.918 & 46,1 & 1.985 & 47,8 & 1.438 & 44,3 \\
\hline & Não respondeu & 760 & 18,3 & 474 & 11,4 & 256 & 7,9 \\
\hline \multirow{8}{*}{ 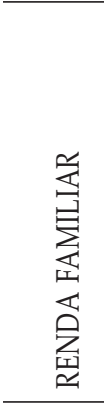 } & Até 1,5 salário mínimo & 279 & 6,7 & 303 & 7,3 & 499 & 15,4 \\
\hline & De 1,5 a 3 salários & 639 & 15,3 & 733 & 17,6 & 647 & 19,9 \\
\hline & De 3 a 4,5 salários & 662 & 15,9 & 742 & 17,9 & 684 & 21,1 \\
\hline & De 4,5 a 6 salários & 513 & 12,3 & 590 & 14,2 & 382 & 11,8 \\
\hline & De 6 a 10 salários & 748 & 18,0 & 673 & 16,2 & 427 & 13,1 \\
\hline & De 10 a 30 salários & 496 & 11,9 & 569 & 13,7 & 307 & 9,5 \\
\hline & Acima de 30 salários & 78 & 1,9 & 71 & 1,7 & 46 & 1,4 \\
\hline & Não respondeu & 748 & 18,0 & 474 & 11,4 & 256 & 7,9 \\
\hline
\end{tabular}

Fonte: Dados da Pesquisa (2020). 
Os discentes que realizaram o exame ENADE nos triênios analisados, são em maioria do sexo masculino, com valores de 53,2\% e $52,2 \%$ nos anos de 2012 e 2018, apenas no ano de 2015 que o sexo feminino foi predominante, mesmo com uma diferença mínima, mas representou $50,1 \%$ do total. Semelhante a esses resultados, dados do Conselho Federal de Contabilidade (CFC) apontam que até o ano de 2018, os profissionais de Contabilidade com registro ativo eram, em maioria, representados por $57,2 \%$ do sexo masculino, enquanto o sexo feminino apresenta-se com um total de $42,8 \%$, mas que existe uma tendência de crescimento entre as mulheres no segmento contábil ao longo dos anos (CFC, 2019).

Os discentes ainda apresentaram, em grande maioria, idades entre 21 e 30 anos, com valores correspondentes a mais de $70 \%$ em ambos os anos analisados, seguida pelas idades entre 31 e 40 anos, com valores que variam de $15 \%$ a $17 \%$, aproximadamente. Mostrando assim, que os discentes convocados para realização do exame, apresentam-se como um público de faixa etária mais jovem até uma idade mediana.

Com relação a cor/etnia, os discentes declararam, em sua maioria, como sendo brancos, com variação aproximada de $40 \%$ a $45 \%$ nos anos analisados, seguido por aqueles que se classificaram como sendo pardos/mulatos, que apresentou crescimento percentual ao longo dos anos, juntamente com os que se classificaram como negros, que apesar da quantidade ainda ser considerada pequena, mas também é possível analisar que houve crescimento percentual dos discentes que se declararam negros.

Quanto a atividade remunerada, a maioria dos discentes, nos anos analisados, afirmou trabalhar integramente (40h semanais ou mais), seguido por aqueles que não desempenham nenhuma atividade remunerada e que além disso, teve uma tendência de crescimento percentual dessa categoria no decorrer dos anos. Os que trabalham mais de $20 \mathrm{~h}$ até $40 \mathrm{~h}$ semanalmente, tiveram uma representatividade média entre $12 \%$ e $13 \%$ dos discentes e as demais categorias obtiveram um resultado que não alcançou 5\% em nenhum dos anos analisados.

Por fim, em relação a composição da renda familiar, não houve diferença expressiva entre as categorias observadas e também houve 
algumas mudanças nas respostas, quando observa-se de um triênio para o outro. Em 2012, os discentes classificaram sua renda familiar como sendo de 6 a 10 salários mínimos, com 18\% do total, já nos anos de 2015 e 2018, essa categoria teve uma queda no número de discentes e em ambos, a maioria dos discentes possuía uma renda familiar de 3 a 4,5 salários mínimos, seguido pelos discentes que estão enquadrados com renda familiar de 1 a 3 salários mínimos.

Os resultados apresentados na presente pesquisa, apontam algumas semelhanças com os estudos realizados por Rodrigues et al. (2017), em que analisaram o perfil sociodemográfico e econômico dos discentes que se submeteram a avaliação ENADE de anos anteriores ao analisado nesse estudo, concluindo que a maioria dos discentes analisados, se enquadrou como sendo do sexo feminino, mesmo que com pouca diferença em relação ao sexo masculino e se declarou como sendo de cor/etnia branca e nesse período analisado, também já havia uma tendência de crescimento entre os que se consideravam pardos/mulatos e negros. Além do mais, outros aspectos foram levados em consideração, como a faixa etária que foi classificada como sendo de idade baixa a média e possuem um nível socioeconômico considerado baixo.

Em seguida, após a análise dos dados referentes ao perfil pessoal, os discentes informaram alguns aspectos relativos ao seu perfil escolar/educacional, apresentando algumas características relacionadas ao tipo e a modalidade do ensino médio, a escolaridade do pai e da mãe, e por fim, as horas de estudo despendidas fora de sala de aula, como representado na Tabela 3 a seguir.

Verifica-se que os discentes cursaram, em sua maioria, todo o ensino médio em escola pública e que houve um crescimento percentual nos triênios de 2012, 2015 e 2018, representado por 39,6\%, 47,7\% e $52,9 \%$, respectivamente. Em contrapartida, o número de discentes que cursaram todo o ensino médio em escola privada, apresentou queda no decorrer dos anos, partindo de 34,1\% em 2012, para 33,6\% em 2015 e por fim, chegando a 32,6\% em 2018. Os discentes que cursaram a maior parte em escola pública e os cursaram a maior parte em escola privada, apresentaram valores semelhantes nos anos analisados e por fim, os que cursaram metade na escola pública e metade na escola privada, representaram valores pequenos, não atingindo valores superiores a $1 \%$ do total de discentes. 
Perfil Discente e o Desempenho Acadêmico dos Cursos de Ciências Contábeis das Universidades Federais Brasileiras

Tabela 3 - Perfil escolar dos discentes do ENADE

\begin{tabular}{|c|c|c|c|c|c|c|c|}
\hline \multirow{2}{*}{\multicolumn{2}{|c|}{$\begin{array}{l}\text { CARACTERÍSTICAS } \\
\text { FREQ. }\end{array}$}} & \multicolumn{2}{|l|}{2012} & \multicolumn{2}{|l|}{2015} & \multicolumn{2}{|l|}{2018} \\
\hline & & \multirow{2}{*}{$\begin{array}{l}\% \\
1.650\end{array}$} & \multirow{2}{*}{$\frac{\text { FREQ. }}{39,6}$} & \multirow{2}{*}{$\begin{array}{l}\% \\
1.980\end{array}$} & \multirow{2}{*}{$\frac{\text { FREQ. }}{47,7}$} & \multirow{2}{*}{$\frac{\%}{1.717}$} & \multirow[b]{2}{*}{52,9} \\
\hline \multirow{6}{*}{ 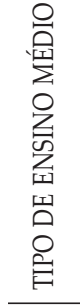 } & Todo em escola pública & & & & & & \\
\hline & Todo em escola privada & 1.420 & 34,1 & 1.397 & 33,6 & 1.059 & 32,6 \\
\hline & A maior parte em escola pública & 151 & 3,6 & 146 & 3,5 & 97 & 3,0 \\
\hline & A maior parte em escola privada & 153 & 3,7 & 143 & 3,4 & 111 & 3,4 \\
\hline & $\begin{array}{l}\text { Metade na escola pública e metade na } \\
\text { escola privada }\end{array}$ & 41 & 1,0 & 9 & 0,2 & 8 & 0,3 \\
\hline & Não respondeu & 748 & 18,0 & 477 & 11,5 & 256 & 7,9 \\
\hline \multirow{6}{*}{ 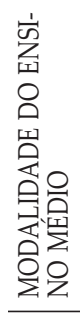 } & Ensino médio tradicional & 2.986 & 71,7 & 3.243 & 78,1 & 2.516 & 77,5 \\
\hline & Profissionalizante técnico & 317 & 7,6 & 326 & 7,8 & 353 & 10,9 \\
\hline & Profissionalizante magistério & 35 & 0,8 & 23 & 0,6 & 22 & 0,7 \\
\hline & $\begin{array}{l}\text { Educação de Jovens e Adultos (EJA) e/ } \\
\text { ou Supletivo }\end{array}$ & 62 & 1,5 & 66 & 1,6 & 76 & 2,3 \\
\hline & Outra modalidade & 12 & 0,3 & 20 & 0,5 & 25 & 0,8 \\
\hline & Não respondeu & 751 & 18,0 & 477 & 11,5 & 256 & 7,9 \\
\hline \multirow{7}{*}{ 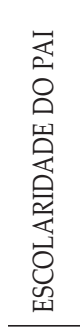 } & Nenhuma & 120 & 2,9 & 171 & 4,1 & 248 & 7,6 \\
\hline & Ens. Fundamental: $1^{\circ}$ ao $5^{\circ}$ ano & 834 & 20,0 & 807 & 19,4 & 631 & 19,4 \\
\hline & Ens. Fundamental: $6^{\circ}$ ao $9^{0}$ ano & 431 & 10,4 & 521 & 12,5 & 401 & 12,3 \\
\hline & Ensino Médio & 1.204 & 28,9 & 1.311 & 31,6 & 1.038 & 32,0 \\
\hline & Ensino Superior & 615 & 14,8 & 632 & 15,2 & 472 & 14,5 \\
\hline & Pós-graduação & 209 & 5,0 & 239 & 5,8 & 202 & 6,2 \\
\hline & Não respondeu & 750 & 18,0 & 474 & 11,4 & 256 & 7,9 \\
\hline \multirow{7}{*}{ 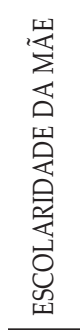 } & Nenhuma & 78 & 1,9 & 99 & 2,4 & 167 & 5,1 \\
\hline & Ens. Fundamental: $1^{\circ}$ ao $5^{0}$ ano & 638 & 15,3 & 644 & 15,5 & 492 & 15,1 \\
\hline & Ens. Fundamental: $6^{\circ}$ ao $9^{0}$ ano & 443 & 10,6 & 525 & 12,6 & 413 & 12,7 \\
\hline & Ensino Médio & 1.297 & 31,2 & 1.380 & 33,2 & 1.090 & 33,6 \\
\hline & Ensino Superior & 620 & 14,9 & 667 & 16,1 & 505 & 15,5 \\
\hline & Pós-graduação & 335 & 8,0 & 366 & 8,8 & 325 & 10,0 \\
\hline & Não respondeu & 752 & 18,1 & 474 & 11,4 & 256 & 7,9 \\
\hline \multirow{6}{*}{ 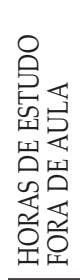 } & Nenhuma & 370 & 8,9 & 313 & 7,5 & 328 & 10,1 \\
\hline & De uma a três horas & 1.803 & 43,3 & 1.943 & 46,8 & 1.458 & 44,9 \\
\hline & De quatro a sete horas & 845 & 20,3 & 925 & 22,3 & 789 & 24,3 \\
\hline & De oito a doze horas & 230 & 5,5 & 320 & 7,7 & 254 & 7,8 \\
\hline & Mais de doze horas & 161 & 3,9 & 177 & 4,3 & 163 & 5,0 \\
\hline & Não respondeu & 754 & 18,1 & 477 & 11,5 & 256 & 7,9 \\
\hline
\end{tabular}

Fonte: Dados da Pesquisa (2020). 
Em relação a modalidade do ensino médio cursado pelos discentes, os resultados apontam que uma grande maioria, cursou o ensino médio tradicional, representado por valores acima de $70 \%$ em ambos os triênios de análise, apresentando crescimento nesses valores e chegando a quase $80 \%$ do total, nos anos de 2015 e 2018 . Seguido pelo ensino médio profissionalizante técnico que, apesar de ainda possuir uma pequena quantidade de discentes, apresentou crescimento no decorrer dos anos analisados, partindo de 7,6\% em 2012, para 7,8\% em 2015 e atingindo os 10,9\% em 2018. Já as demais modalidades de ensino médio, apresentaram valores considerados pequenos, em comparação as modalidades já mencionadas, não chegando ao somatório de $5 \%$ do total em nenhum dos anos analisados.

No tocante a escolaridade do pai dos discentes, em ambos os triênios, a maioria afirmou que o pai possui ensino médio completo, com uma média de $30 \%$, aproximadamente, acompanhado de ensino fundamental de $1^{\underline{0}}$ ao $5^{\circ}$ ano, apresentando uma média dos triênios de, aproximadamente, $20 \%$ do total. A quantidade de pai que possui ensino superior, praticamente permaneceu a mesma no decorrer dos anos, apresentando uma pequena queda no triênio de 2018, já os que possuem pós-graduação, apresentou um pequeno crescimento ao longo dos anos e outro aspecto a ser levando em consideração, que houve aumento daqueles que não possuem nenhuma escolaridade, partindo de 2,9\% em 2012 e chegando a 7,6\% em 2018.

Nessa perspectiva, a escolaridade da mãe apresentou alguns resultados semelhantes a escolaridade do pai, tendo em vista que a maioria dos discentes afirmou que a escolaridade de sua mãe se concentra na categoria de ensino médio completo, com uma média aproximada de $32 \%$ do total, bem como as mães que não possuem nenhum tipo de escolaridade, apresentou aumento no decorrer dos anos, mesmo que tenha sido inferior ao quantitativo do pai. Entretanto, a escolaridade da mãe referente ao ensino fundamental de $1^{\underline{o}}$ ao $5^{\underline{o}}$ ano, somente foi maior no triênio de 2012, em comparação ao ensino superior, pois nos triênios seguintes, a quantidade de mães que possuem ensino superior apresentou valores maiores, diferentemente da escolaridade dos pais para essa categoria, como também, o número de mães que cursaram pós-graduação, é maior que a quantidade de pais. Dessa forma, pode-se concluir que a mãe 
dos discentes analisados, possui um maior nível de escolaridade, se comparado com o nível de escolaridade do pai.

Os discentes ainda relataram o total de horas fora da sala de aula que disponibilizam para os estudos por semana e a maioria informou, em ambos os triênios, disponibilizar de uma a três horas de estudo, representado por uma média de $45 \%$ dos discentes e em seguida, apresentam-se os discentes que disponibilizaram de quatro a sete horas por semana, com uma média dos triênios de, aproximadamente, $22 \%$ do total. Na sequência, se enquadram os discentes que não disponibilizam nenhuma hora extra sala de aula por semana, com valores que vão de 8,9\% em 2012 até 10,1\% em 2018 e as demais categorias juntas e por triênio, de oito a doze horas e mais de doze horas, não chegam aos 13\% dos discentes. Esses resultados refletem uma perspectiva de baixa disponibilidade para estudos fora de sala, ou seja, os discentes analisados ainda estão disponibilizando poucas horas de estudo fora da sala de aula.

Corroborando a pesquisa de Rodrigues et al. (2017) que, ao estudarem o desempenho acadêmico por meio de variáveis relacionadas a coordenação de cursos de Ciências Contábeis, puderam analisar características relacionadas aos discentes que participaram do exame ENADE nos anos de 2006 e 2009, concluindo assim, que já havia uma predisposição aos discentes possuírem sua origem escolar, em grande maioria, do ensino médio tradicional e público, como também, notou-se que em relação a escolaridade do pai e da mãe, os mesmos ainda apresentam escolaridade considerada baixa, mas que em comparação, a mãe ainda possui nível de escolaridade mais alto que o pai e por fim, as horas extra sala de aula dedicadas pelos discentes, ainda é apontado como sendo insatisfatório.

Ainda de acordo com as características dos discentes dos cursos analisados, cabe ressaltar a média que esses discentes atingiram, que culminou na nota geral do ENADE por aluno. A nota geral do exame compreende a nota padronizada dos discentes na parte dos conhecimentos específicos, que equivale a $75 \%$ da nota e da parte de formação geral, que contribui com $25 \%$ para a nota final. Para a nota dos discentes são consideradas as pontuações de 0 (zero) a 100 (cem), incluindo conhecimentos específicos e formação geral, além do mais e para melhor visualização e as pontuações foram categorizadas seguindo um padrão e os resultados estão representados a seguir. 
Tabela 4 - Nota Geral do ENADE por aluno

\begin{tabular}{l|l|l|l|l|l|l}
\hline \multirow{2}{*}{ PONTUAÇÃO } & \multicolumn{2}{|l|}{ 2012 } & \multicolumn{2}{l}{ 2015 } & \multicolumn{2}{l}{2018} \\
\cline { 2 - 7 } & FREQ. & $\%$ & FREQ. & $\%$ & FREQ. & $\%$ \\
\hline 0 pontos & 37 & 0,9 & 4 & 0,1 & 6 & 0,2 \\
\hline Até 20 pontos & 266 & 6,4 & 61 & 1,5 & 117 & 3,6 \\
\hline Entre 20,1 e 40 pontos & 1.469 & 35,3 & 876 & 21,1 & 1.090 & 33,6 \\
\hline Entre 40,1 e 60 pontos & 1.242 & 29,8 & 1.820 & 43,8 & 1.286 & 39,6 \\
\hline Entre 60,1 e 80 pontos & 295 & 7,1 & 727 & 17,5 & 353 & 10,8 \\
\hline Entre 80,1 e 100 pontos & 24 & 0,6 & 22 & 0,5 & 5 & 0,2 \\
\hline NA & 830 & 19,9 & 645 & 15,5 & 391 & 12,0 \\
\hline Total & 4.163 & 100,0 & 4.155 & 100,0 & 3.248 & $100, c$ \\
\hline
\end{tabular}

Fonte: Dados da Pesquisa (2020).

Percebe-se a evolução da pontuação atingida pelos discentes nos últimos triênios do ENADE e destaca-se que o número de discentes que zeraram o exame, mesmo que considerado um resultado baixo em comparação com as demais classificações, teve uma queda do triênio de 2012 para os demais triênios considerados e em uma classificação considerada baixa, os discentes que atingiram até 20 pontos, também apresentaram queda de 2012 em comparação com 2015, voltando a crescer novamente em 2018.

No que tange o triênio de 2012, a maior quantidade de discentes estão classificados na categoria de pontuação entre 20,1 e 40 pontos, seguida da categoria entre 40,1 e 60 pontos, apresentando valores aproximados e levando em consideração o somatório dessas categorias, pode-se afirmar que, aproximadamente, 65\% dos discentes estão enquadrados numa categoria considerada baixa/média de pontuação e os que estão classificados nas categorias mais altas, isto é, acima de 60 pontos até 100 pontos, não chegam nem a $8 \%$ da pontuação total.

Em comparação com o triênio de 2012, pode-se afirmar que houve uma tendência de crescimento na pontuação dos discentes nos triênios de 2015 e 2018, tendo em vista que a maioria dos discentes desse período, atingiram a categoria de 40,1 e 60 pontos, como também, ocorreu crescimento na categoria que corresponde 
de 60,1 a 80 pontos, especialmente no triênio de 2015, entretanto, nos dois últimos triênios, houve uma queda no número de discentes que alcançaram a categoria de 80,1 a 100 pontos, principalmente no triênio de 2018.

De modo geral, é possível constatar que houve uma evolução na pontuação dos discentes dos cursos de Ciências Contábeis das universidades federais brasileiras, com uma tendência de crescimento da pontuação no decorrer dos triênios analisados, especialmente no triênio de 2015. Porém, a maior parte dos discentes ainda se encontra enquadrada nas categorias de pontuação consideradas baixas e medianas, e uma pequena parcela desses discentes, consegue atingir pontuações consideradas altas, o que pode refletir em notas mais baixas e, consequentemente, em conceitos ENADE mais baixos para os cursos, tendo em vista que, a pontuação do discente no exame, afeta significativamente o conceito que é atribuído ao curso em que o candidato que se submeterá a avaliação está representando.

Por meio dos estudos de Camargo et al. (2016) é possível corroborar os resultados apresentados na presente pesquisa, tendo que em vista que os discentes que realizaram o exame ENADE em anos anteriores, em geral, não obtiveram notas consideradas altas, apresentando assim, proficiências muito baixas, tanto na parte de conhecimentos específicos como na parte de conhecimentos gerais, o que resulta em um baixo desempenho, em consequência ao fato dos discentes relatarem um alto grau de dificuldade do exame e não possuírem habilidades suficientes para dispor de maior êxito na realização da prova.

Com o intuito de atingir o objetivo geral do estudo, realizou-se a técnica de correlação de Pearson para identificar a relação entre as variáveis que compreendem o perfil discente e o desempenho acadêmico dos cursos de Ciências Contábeis das universidades federais brasileiras, como apresentado a seguir. 
Tabela 5 - Matriz de Correlação

\begin{tabular}{|c|c|c|c|c|c|c|c|c|c|c|}
\hline $\begin{array}{l}\text { VARIÁ- } \\
\text { VEIS }\end{array}$ & 1 & 2 & 3 & 4 & 5 & 6 & 7 & 8 & 9 & 10 \\
\hline $\begin{array}{l}\text { 1.NT_GE- } \\
\text { RAL }\end{array}$ & 1 & & & & & & & & & \\
\hline 2.SEX & $0.020^{*}$ & 1 & & & & & & & & \\
\hline 3.IDAD & $-0.082^{*}$ & $-0.143^{*}$ & 1 & & & & & & & \\
\hline $\begin{array}{l}\text { 4.COR_ } \\
\text { ET }\end{array}$ & $0.120^{*}$ & $0.019^{*}$ & $0.021^{*}$ & 1 & & & & & & \\
\hline $\begin{array}{l}\text { 5.AT } \\
\text { REM }\end{array}$ & $0.175^{*}$ & $-0.056^{*}$ & 0.118 & $0.144^{*}$ & 1 & & & & & \\
\hline 6.REND & $0.240^{*}$ & $-0.067^{*}$ & $-0.042^{*}$ & $-0.004^{*}$ & $0.344^{*}$ & 1 & & & & \\
\hline $\begin{array}{l}\text { 7.ESC_ } \\
\text { PAI }\end{array}$ & $0.263^{*}$ & $-0.016^{*}$ & $-0.251^{*}$ & $0.097^{*}$ & $0.212^{*}$ & $0.524^{*}$ & 1 & & & \\
\hline $\begin{array}{l}\text { 8.ESC } \\
\text { MAE }\end{array}$ & $0.256^{*}$ & $0.015^{*}$ & $-0.281^{*}$ & $0.134^{*}$ & $0.215^{*}$ & $0.500^{*}$ & $0.685^{*}$ & 1 & & \\
\hline 9.TP_ENS & $0.163^{*}$ & $-0.029^{*}$ & -0.065 & $0.086^{*}$ & $0.147^{*}$ & $0.320^{*}$ & $0.377^{*}$ & $0.380^{*}$ & 1 & \\
\hline $\begin{array}{l}\text { 10.MOD_ } \\
\text { ENS }\end{array}$ & $0.159^{*}$ & $-0.003^{*}$ & $0.182^{*}$ & $0.177^{*}$ & $0.211^{*}$ & $0.163^{*}$ & $0.146^{*}$ & $0.147^{*}$ & $0.144^{*}$ & 1 \\
\hline $\begin{array}{l}\text { 11.HR_ } \\
\text { EST }\end{array}$ & $0.308^{*}$ & $0.064^{*}$ & $-0.041^{*}$ & $0.189^{*}$ & $0.125^{*}$ & $0.214^{*}$ & $0.255^{*}$ & $0.271^{*}$ & $0.166^{*}$ & 0.22 \\
\hline
\end{tabular}

(*) Significância ao nível de 1\%

Fonte: Dados da Pesquisa (2020).

Pela matriz de correlação das variáveis utilizadas, destacada na Tabela 5, pode-se perceber que existe uma quantidade elevada de variáveis que estão correlacionadas, entretanto, pelos valores dos coeficientes de correlação, percebe-se que os mesmos não expressam valores altos de correlação, ou seja, apresentam correlações de intensidade baixa a moderada e infere-se ainda, a inexistência de multicolinearidade, de acordo com Gujarati e Porter (2011).

Analisando as variáveis discentes, de modo geral, apresentaram correlações mais baixas no tocante a nota geral do aluno no exame ENADE, não chegando a atingir o coeficiente de correlação $\geq 0,4$, considerado por Santos (2018) como uma correlação de intensidade baixa ou fraca. Ambas as variáveis desse grupo, se mostraram relacionadas positivamente com a nota geral e tendem a caminhar no 
mesmo sentido da variável dependente, entretanto, a variável idade apresenta uma relação negativa, representada por um coeficiente de $-0,828$, ou seja, existe uma relação inversa para essas variáveis, tendo em vista que, à medida que a idade aumenta, a nota geral do candidato diminui ou vice versa.

Infere-se então, que o conjunto de variáveis discentes possuem significância estatística com o desempenho acadêmico e estão correlacionados entre si, tanto quando são analisadas individualmente, como analisadas de forma grupal, demonstrado pela quantidade elevada de variáveis que estão correlacionadas. Assim, as variáveis discentes que correspondem ao perfil sociodemográfico e escolar, analisadas na presente pesquisa, são consideradas como determinantes para influenciar o desempenho acadêmico dos cursos de Ciências Contábeis das universidades federais brasileiras.

Os resultados apresentados por Miranda et al. (2015) e Moura, Miranda e Pereira (2015) possuem semelhanças e divergências com o presente estudo, no que tange as variáveis discentes que possuem relação e podem influenciar o desempenho acadêmico dos discentes, com destaque para as variáveis que apresentam correlação, como renda familiar, atividade remunerada e horas de estudo fora de sala de aula. Entretanto, as variáveis sociodemográficas de gênero, idade, cor/etnia e escolaridade dos pais, não possuem relação entre si e nem podem influenciar o desempenho acadêmico dos discentes.

Demais estudos, como os de Abdullah (2011) e Nyikahadzoi et al. (2013), apresentam variáveis discentes ligadas ao desempenho acadêmico e que possuem divergências equivalentes as destacadas nessa pesquisa, tanto nas variáveis sociodemográficas, quanto nas variáveis educacionais. Sugere-se assim, que os resultados aqui apresentados não podem ser generalizados para demais instituições ou situações analisadas, deve-se levar em consideração o campo de aplicação que está sendo considerado.

\section{CONSIDERAÇões FINAIS}

O estudo encontra-se pautado na área de ensino da contabilidade, com foco na relação entre os atributos que compreendem o perfil discente e o desempenho acadêmico de cursos nessa área. Assim, a pesquisa busca atender ao objetivo de identificar a relação entre o 
perfil discente e o desempenho acadêmico dos cursos de Ciências Contábeis das Universidades Federais Brasileiras.

O perfil discente desses cursos foi analisado mediante seu perfil sociodemográfico e escolar, concluindo que os discentes, em sua maioria, concentram-se nas regiões Nordeste e Sudeste do país, são do sexo masculino, possuem idade entre 21 e 30 anos, se classificam como de cor/etnia branca, trabalham integralmente (40h semanais ou mais) e possuem renda familiar de 3 a 4,5 salários mínimos.

Já em relação a escolaridade, a maioria dos discentes cursou todo o ensino médio em escola pública e pelo modelo tradicional, os pais possuem escolaridade de ensino médio completo e tem dedicação de uma a três horas de estudo fora da sala de aula. No que tange a nota geral no ENADE, os discentes ainda possuem médias consideradas baixas e medianas, e uma pequena parcela, consegue atingir pontuações consideradas altas, o que pode refletir em seu desempenho acadêmico mais baixo ou mais alto.

Constatou-se ainda que, após a análise estatística por meio da correlação, os aspectos ligados ao perfil sociodemográfico e escolar dos discentes analisados, estão correlacionados estatisticamente entre si e com a nota geral do discente, possuindo então, relação significativa com o desempenho acadêmico dos cursos de Ciências Contábeis das universidades federais brasileiras.

Dessa forma, pode-se inferir que o objetivo do estudo foi alcançado, tendo em vista que pôde-se traçar o perfil discente dos cursos de Ciências Contábeis das universidades federais brasileiras, de acordo com os seus aspectos sociodemográficos e escolares, e por meio da análise de correlação, identificou-se a relação desses aspectos docentes com o desempenho acadêmico dos cursos analisados.

Nesse sentido, a pesquisa traz contribuições no incremento das discussões relacionadas a temática e estender a produção científica na área, tendo em vista a escassez de estudos que apresentem fatores relacionados ao perfil discente que influenciam o desempenho acadêmico das instituições de ensino, bem como poder auxiliar na busca por melhorias no processo de ensino-aprendizagem nos âmbitos do ensino, pesquisa e extensão, voltados principalmente para o público discente e possuem relação com o desempenho acadêmico. 
Entretanto, no processo de desenvolvimento do estudo, algumas limitações podem ser destacadas, especialmente em virtude da escassez de estudos direcionados para influência dos aspectos discentes no desempenho acadêmico das instituições de ensino, bem como dificuldade em coletar alguns dados que não foram disponibilizados ou não estão em conformidade com os demais. Assim, sugere-se para realização de pesquisas futuras, a análise com discentes em faculdades das demais categorias administrativas e em outras modalidades de ensino, que proporcionaria uma amostra mais abrangente.

\section{REFERÊNCIAS}

ABDULLAH, A. M. Factors affecting business students' performance in arab open university: the case of Kuwait. International Journal of Business and Management, v. 6, n. 5, p. 146, 2011.

ABINA, M. B.; UTHMAN, A. B. Internal Brand Equity of Universities and Students' academic Performance: an Empirical Survey of Accounting Students. Global Management Review, v. 12, n. 1, 2018.

ALANZI, K. A.; ALFRAIH, M. M. Does accumulated knowledge impact academic performance in cost accounting? Journal of International Education in Business, v. 10, n. 1, p. 02-11, 2017.

ALVES, F. S.; FARIAS, M. R. S.; FARIAS, K. T. R. Desempenho acadêmico em Métodos Quantitativos nos cursos de Ciências Contábeis. Enfoque: Reflexão Contábil, v. 34, n. 2, p. 37-50, maio/ago., 2015.

ARAújO, E. A. T.; CAMARGOS, M. A.; CAMARGOS, M. C. S.; DIAS, A. T. Desempenho acadêmico de discentes do curso de Ciências Contábeis: uma análise dos seus fatores determinantes em uma IES privada. Revista Contabilidade Vista \& Revista, v. 24, n. 1, p. 60-83, jan./mar. 2013.

CAMARGO, R. V. W.; CAMARGO, R. C. C. P.; ANDRADE, D. F.; BORNIA, A. C. Desempenho dos alunos de Ciências Contábeis na prova Enade 2012: uma aplicação da Teoria da Reposta ao Item. Revista de Educação e Pesquisa em Contabilidade - REPeC, v. 10, n. 3, p. 332-355, jul./set. 2016.

CONSELHO FEDERAL DE CONTABILIDADE. CFC. Pelo respeito e pelos direitos: CFC enaltece a importância da mulher na contabilidade. 2019. Disponível em: <https://cfc.org.br/ noticias/pelo-respeito-e-pelos-direitos-cfc-enaltece-a-importancia-da-mulher-na-contabilidade/>. Acesso em: 14 fev. 2020.

CORNACHIONE JUNIOR, E. B.; DA CUNHA, J. V. A.; DE LUCA, M. M. M.; OTT, E. O bom é meu, o ruim é seu: perspectivas da teoria da atribuição sobre o desempenho acadêmico de alunos da graduação em Ciências Contábeis. Revista Contabilidade \& Finanças - USP, v. 21, n. 53, p. 1-24, mai./ago., 2010. 
DAS, B. Higher education on the cross-road. Social Science International, v. 30, n. 2, p. 417-426, 2014.

FERREIRA, M. A. Determinantes do desempenho discente no ENADE em cursos de Ciências Contábeis. 2015. 124 f. Dissertação (Mestrado em Ciências Contábeis) - Faculdade de Ciências Contábeis, Universidade Federal de Uberlândia, Uberlândia, MG, 2015.

GARKAZ, M.; BANIMAHD, B.; ESMAEILI, H. Factors Affecting Accounting Students' Performance: The Case Of Students At The Islamic Azad University. Procedia-Social and Behavioral Sciences, v. 29, p. 122-128, 2011.

GIL, A. C. Didática do ensino superior. São Paulo: Atlas, 2012.

GLEWWE, P. W.; HANUSHEK, E. A.; HUMPAGE, S.; RAVINA, R. School resources and educational outcomes in developing countries: a review of the literature from 1990 to 2010. National Bureau of Economic Research, n. 17.554, 2011.

GUJARATI, D. N.; PORTER, D. C. Econometria básica. 5 ed. Porto Alegre: AMGH, 924p, 2011. IUDÍCIBUS, S. Teoria da Contabilidade. São Paulo, 11ª ed., 2015.

KATSIKAS, E.; PANAGIOTIDIS, T. Student status and academic performance: Accounting for the symptom of long duration of studies in Greece. Studies in Educational Evaluation, v. 37, n. 2, p. 152-161, 2011.

KAWAUCHE, R.; VIEIRA, A. M.; MENDONÇA NETO, O. R. Relações interpessoais e atuação profissional: A perspectiva dos contabilistas. Revista Eletrônica Gestão e Serviços, v. 6, n. 2, p. 1289-1314, 2015.

MANIATES, M. Higher education for a post-growth world. The Chronicle Review, v. 1, n. 7, p. 10-12, 2017.

MENDONÇA NETO, O. R.; VIEIRA, A. M.; ANTUNES, M. T. P. Industrialização da educação, edtech e prática docente. Eccos Revista Científica, v. 3, p. 149-170, 2018.

MIRANDA, G. J.; MAMEDE, S. P. N.; MARQUES, A. V. C.; ROGERS, P. Determinantes do desempenho acadêmico em ciências contábeis: uma análise de variáveis comportamentais. In: XIV Congresso USP de Controladoria e Contabilidade e XI Congresso USP de Iniciação Científica, 2014, São Paulo. Anais... São Paulo, 2014.

MIRANDA, C. S.; ARAUJO, A. M. P.; MIRANDA, R. A. M. Perfil e expectativas dos ingressantes do curso de Ciências Contábeis: um estudo em instituições de ensino superior do interior paulista. Revista de Gestão, Finanças e Contabilidade, v. 5, n. 1, p. 04-20, Edição Especial: 5ㅜa ano da RGFC, 2015.

MIRANDA, G. J.; LEMOS, K. C. S.; OLIVEIRA, A. S.; FERREIRA, M. A. Determinantes do Desempenho Acadêmico na Área de Negócios. Meta: Avaliação, Rio de Janeiro, v. 7, n. 20, p. 175-209, maio/ago. 2015.

MIRANDA, G. J.; DOS REIS, C. F.; FREITAS, S. C. Ansiedade e Desempenho Acadêmico: um estudo com alunos de Ciências Contábeis. In: XVII Congresso USP de Controladoria e Contabilidade, 2017, São Paulo. Anais... São Paulo, 2017.

MOURA, A. C. R.; MIRANDA, G. J.; PEREIRA, J. M. Desempenho acadêmico em ciências contábeis: turno noturno versus diurno. Enfoque: Reflexão Contábil, v. 34, n. 1, p. 57-70, jan./abr., 2015.

NEVES, C. E. B.; SAMPAIO, H.; HERINGER, R. A institucionalização da pesquisa sobre ensino superior no Brasil. Revista Brasileira de Sociologia, v. 06, n. 12, jan./abr., 2018. 
NYIKAHADZOI, L.; MATAMANDE, W.; TADERERA, E.; MANDIMIKA, E. Determinants of students' academic performance in four selected accounting courses at University of Zimbabwe. Research in Higher Education Journal, v. 21, p.1-9, 2013.

NOGUEIRA, D. R.; COSTA, J. M.; TAKAMATSU, R. T.; DOS REIS, L. G. Fatores que impactam o desempenho acadêmico: uma análise com discentes do curso de ciências contábeis no ensino presencial. Revista de Informação Contábil - RIC, v. 7, n. 3, p. 51-62, jul./set., 2013. RIBEIRO, J. L. L. S. Avaliação das Universidades Brasileiras: as possibilidades de avaliar e as dificuldades de ser avaliado. Avaliação, v. 16, n. 1, p. 57-71, 2011.

RISTOFF, D. I. Algumas definições de avaliação. Avaliação, v. 8, n. 1, p. 19-30, mar. 2003.

RODRIGUES, D. S.; SANTOS, N. A.; SANTANA, M. S.; LEMES, A. P. M. Diferenças entre gênero, etnia e perfil socioeconômico no Exame Nacional de Desempenho do Estudante do curso de Ciências Contábeis. Revista Contemporânea de Contabilidade, v. 14, n. 33, p. 101117, set./dez., 2017.

SANTOS, A. P.; CERQUEIRA, E. A. Ensino Superior: trajetória histórica e políticas recentes. In: CONGRESSO INTERNACIONAL SOBRE GESTÃO UNIVERSITÁRIA NA AMÉRICA DO SUL - UFSC, 11., 2009. Anais... Florianópolis/SC, 2009.

SANTOS, N. M. Determinantes do desempenho acadêmico dos alunos dos cursos de Ciências Contábeis. 2012. 257 f. Tese (Doutorado em Controladoria e Contabilidade) - Faculdade de Economia, Administração e Contabilidade, Universidade de São Paulo, São Paulo, SP, 2012.

SANTOS, C. M. L. S. A. Estatística Descritiva: Manual de Autoaprendizagem. Lisboa: Edições Sílabo. 3를 2018.

SILVA, G. M. S.; ROSA, F. S. O curso de Ciências Contábeis no Brasil: um estudo sobre as Políticas Públicas de ensino superior e seu reflexo na oferta e na demanda no período de 2001 a 2013. Revista de Gestão, Finanças e Contabilidade, v. 6, n. 2, p. 94-111, maio/ago., 2016.

SOARES, S. V.; SILVA, V. P.; NOVA, S. P. C. C.; GOIS, A. D. Programas de pós-graduação em Contabilidade: semelhanças e diferenças da produção bibliográfica. Race: Revista de Administração, Contabilidade e Economia, v. 17, n. 2, p. 695-732, 2018.

UYAR, A.; GÜNGÖRMÜŞ, A. H. Factors associated with student performance in financial accounting course. European Journal of Economic and Political Studies, v. 4, n. 2, p. 139$154,2011$.

VASCONCELOS, L. Economia da educação. In: ARVATE, P. R.; BIDERMAN, C. (Org.). Economia do setor público no Brasil. Rio de Janeiro: Campus: Elsevier, 2010.

Recebido em: 2-3-2021

Aprovado em: 2-12-2021

Avaliado pelo sistema double blind review.

Disponível em http://mjs.metodista.br/index.php/roc 